\title{
ENTREVISTA
}

\section{La Masonería en la villa de Avilés}

El investigador Ricardo Fernández Rodríguez ha defendido un Proyecto de Investigación en el Título Máster "Historia de la Masonería en España y América", cuyo título es "La Masonería en la villa de Avilés", en la Universidad Nacional de Educación a Distancia en España, el 1 de septiembre de 2015. Ricardo Fernández nació en 1969 en Gijón, Asturias, España.

El autor nos ha concedido la siguiente entrevista.

¿Cuáles fueron los motivos que le llevaron a enfocar su investigación hacia la Masonería?

No puedo hablar de una motivación única. En mi caso hay un matiz personal ineludible a la hora de hablar de esa motivación. Me incorporé a una logia muy joven, con 24 años, allá por el año 1994, y tras un largo periplo terminé participando en la fundación en Gijón de un taller adscrito al Gran Oriente de Francia: la logia Rosario Acuña. Si en un primer momento me atrajo de la institución la ligazón que en España tuvo en un determinado momento con el republicanismo, paulatinamente me fui interesando por la historia de la asociación.

He tenido la suerte de conocer tanto en Francia como en España a personas que profesan un verdadero amor por el conocimiento del pasado de esta entidad. Y me he contagiado felizmente.

Durante años he convivido -como todos, supongo-, con una cierta hagiografía histórica de la masonería. Creo que nos consta la existencia de este fenómeno y la enfermiza persistencia a veces en la búsqueda y etiquetado de masones, bien con el ánimo de ensalzar o de criticar a la entidad, atribuyéndole según el caso un timbre de nobleza o un grado determinado de perversión. También puedo decir en este sentido que he tenido la suerte de haberme encontrado con investigadores ajenos a ese viejo planteamiento que tan poco tiene que ver con la labor investigadora, y he podido acercarme a esa historia masónica de otro modo.

Partiendo de que también en el ámbito historiográfico se ha de evolucionar en la búsqueda de la verdad sin aditamentos, ésa también ha sido otra motivación que me ha llevado a guiar mis pasos a través de un espacio que siempre me ha gustado, la historia, pero que no ha constituido mi dedicación profesional. Este es un extremo importante a destacar, pues a pesar de que uno estudia, lee y escucha, no puede dejar de reconocer sus limitaciones frente a figuras más autorizadas que han hecho de su vida un ejercicio modesto y honesto de dedicación al conocimiento. En mi caso creo que también podría añadir como 
última motivación el hecho de querer aprender sin más.

¿Cuáles fueron las fuentes que ha utilizado?

A lo largo del tiempo me he ido proveyendo de una biblioteca personal más escogida que voluminosa. Hay curiosidades antimasónicas que procuro coleccionar que me han sido de cierta utilidad a la hora de formarme una noción general en torno a la entidad masónica. He tenido además la fortuna de poder localizar a familiares directos de personalidades destacadas de la masonería avilesina, algo que me ha permitido también rescatar en cierto modo una pequeña parte de la memoria histórica colectiva a través del acopio de documentos diversos, entre los que he podido incorporar algún material fotográfico creo que muy interesante. Curiosamente mi trabajo ha coincidido en el tiempo con el desarrollo de otra investigación a cargo de Pablo Martínez Corral -Memoria y olvido en la Quinta Pedregal-, esta por supuesto mucho más ambiciosa, que ve la luz precisamente estos días. Esta coincidencia me ha permitido pedir y recibir la generosa ayuda del autor, que me ha permitido acceder a algunas de las acciones represoras de las que fueron objeto personas de la talla de Elceario Mariño, protagonista destacado de la masonería avilesina del primer tercio del siglo XX. Evidentemente he recurrido al Centro Documental de la Memoria Histórica, que en el caso que nos ocupa conserva la totalidad de los procedimientos incoados por el Tribunal Especial contra los nueve componentes del Triángulo avilesino José Rizal, e incluso un buen número de fichas personales de buena parte de los integrantes de la Logia Concordia, cuya existencia efímera se desarrolló a finales del siglo XIX, y respecto a las cuales merece la pena destacar el hecho de encontrarse fallecidos ya al tiempo de desarrollarse la concienzuda labor de los funcionarios policiales.

Entre las fuentes citaba antes la biblioteca personal, y en este punto merece la pena destacar la existencia de dos trabajos sin los cuales, creo, es difícil por no decir imposible, aproximarse al conocimiento de la masonería asturiana desde su aparición a mediados del siglo XIX. Me refiero a las tesis doctorales de Doña Victoria Hidalgo Nieto y Don Yván Pozuelo Andrés, trabajos para mí de cabecera y que han hecho las veces de brújula a la hora de llevar a cabo mi proyecto.

¿Cuáles fueron las principales dificultades con las que se ha encontrado? ¿Cómo las ha superado?

Quizá la primera dificultad fue seleccionar un tema sobre el cual poder desarrollar un trabajo susceptible de aportar algo, por pequeño que fuera. Inicialmente pensé en la figura de Elceario Mariño Llames, con una dimensión política poco conocida y sobre el que ya habían hecho sendas aportaciones tanto Yván Pozuelo como Pablo M. Corral. Finalmente me decanté sin embargo por la masonería avilesina en su conjunto, que ya había sido 
esbozada en su desarrollo por las dos tesis doctorales a las que antes he hecho referencia.

Las principales dificultades se presentaron en el acercamiento a los familiares, reticentes en algunos casos -algo totalmente explicable-. Tuve la suerte de participar en la organización de una exposición sobre patrimonio masónico en la ciudad de Avilés, lo que permitió publicitar, creo que por primera vez, la figura de Elceario Mariño. Eso me permitió darme a conocer a sus descendientes y acercarme a ellos. A pesar de todo, me queda una espina clavada que es no haber podido conversar con el único hijo de Elceario que sobrevive, aunque no desisto en mi empeño. En cualquier caso no tengo más que palabras de agradecimiento para estas personas, que creo han entendido que hay una parte del pasado que nos pertenece a todos y no puede perderse en el olvido.

¿Cuáles fueron las principales problemáticas históricas que su trabajo ha resuelto?

Avilés no destaca por ser un epicentro de la masonería asturiana. Tanto en el siglo XIX como en el XX ha habido una tibia presencia masónica a pesar de ser uno de los motores económicos y demográficos de Asturias. Dos logias inicialmente, que son una sucesión propiamente dicha y no dos talleres independientes. Y un triángulo en los años treinta del siglo XX que tiene una cortísima vida, pues apenas sí supera lo seis meses. Pero esta última experiencia ha permitido descubrir una figura relevante en la pequeña historia de la masonería asturiana a la que ya me he referido, Elceario Mariño Llames. La información existente aparece dispersa y diluida en la Causa General, y en los expedientes incoados a los integrantes del Triángulo José Rizal. La incorporación de los testimonios familiares ha permitido reconstruir buena parte de la existencia de ese triángulo, y sobre todo el proceso de disolución y desaparición en Avilés, al finalizar la Guerra Civil con la caída del frente norte en octubre de 1937, de una masonería que apenas sí tuvo solidez. Y aunque tenga un componente anecdótico, surge además otro detalle que se apunta en el trabajo como una posibilidad sobre la que desarrollar una labor de investigación más profunda: La existencia de un posible nexo entre las militancias masónicas del siglo XIX y XX en Avilés a través de la figura del padre del propio Elceario Mariño, posible miembro de la Logia Concordia en 1887.

¿Por favor, podría resumir la esencia de su Tesis en dos líneas?

Trato de aproximarme a la masonería que conoció la villa de Avilés, un tímido intento que no cuajó nunca pero que dejó, sobre todo en la experiencia de los años treinta, algún perfil personal digno de estudio.

¿Cuáles fueron las lecciones, a todos los niveles, personal y profesional, que usted ha 
deducido de su experiencia investigativa?

Este trabajo se ha enmarcado en el desarrollo de un proyecto universitario con el que verdaderamente he disfrutado. Lo he disfrutado tanto que la estructuración definitiva de toda la información recopilada durante bastante tiempo, la he realizado durante las vacaciones estivales. Digo esto porque realmente la insistencia y persistencia desarrolladas a la hora de recopilar la información no las he vivido como un sacrificio: Me ha entusiasmado. Es decir, a título personal creo que he hecho algo que no es más que una pequeña aportación pero con la que me he sentido realizado, satisfecho. Quizá puedo decir que he elaborado algo que me aporta un conocimiento y también felicidad. Deseo que quienes puedan leerlo también lleguen a participar de esa vivencia aun a pesar de que esta tenga un componente personal, íntimo, y quizá por ello difícil de transferir.

Desde un punto de vista profesional mantengo el sentimiento de humildad. Para mí es un paso importante que me ha permitido acercarme a un ámbito que siempre me ha gustado, y acercarme al Centro de Estudios Históricos de la Masonería Española. Me queda además el anhelo de continuar por la misma senda, pensando en nuevos proyectos y en desarrollar alguna que otra nueva idea.

¿Ahora, cuáles son sus proyectos profesionales?

Cuando comencé a trabajar en este proyecto merced a la acertadísima sugerencia y consejo de un buen amigo -es algo que no había dicho antes-, me hallaba trabajando en otro proyecto historiográfico en el que el que el trazo fundamental ya está realizado fuera de nuestras fronteras, especialmente en Francia. Me refiero al desarrollo histórico del sistema filosófico inicial con el que se dotaron las primeras logias aparecidas en el continente europeo en el siglo XVIII. Retomaré ese proyecto, que tiene una dimensión un tanto ambiciosa, para explorar una determinada esencia y sensibilidad ritual, si bien siguiendo la estela de otros autores de referencia, en particular Charles Porset, Ludovic Marcos y Pierre Mollier. Estoy seguro de que entre medias surgirán otros proyectos, pues es lo que sucede continuamente, y seguiré participando de una experiencia que me resulta apasionante y aprendiendo. Sobre todo aprendiendo.

¿Quisiera destacar algún aspecto que no se ha contemplado y que usted consideraría digno de reseñar?

Creo que lo que no se haya contemplado expresamente puede deducirse perfectamente del contenido de la entrevista: la gratitud.

Y digo esto porque si algo me ha dejado este trabajo además de una satisfacción determinada y concreta, es un sentimiento vasto de gratitud que se reparte entre quienes han 
escrito los trabajos que he leído y me han ayudado a saber un poco más; entre quienes han abierto su corazón y se han sincerado para hacerme partícipe del dolor acumulado en una familia; y entre quienes me han animado continuamente para que siguiera adelante, permitiéndome descubrir algo que hasta la fecha desconocía.

Esta entrevista se efectúo de forma telemática el 29 de Noviembre de 2015.

Autores de la entrevista: Ricardo Martínez Esquivel e Yván Pozuelo Andrés, Director y Editor de REHMLAC+.

DOI: http://dx.doi.org/10.15517/rehmlac.v8i1.24286 